\title{
Philadelphia Chromosome Positive Chronic Myelogenous Leukemia in A Child: A Case Report
}

\author{
Aparajita Mishra $\cdot$ Kalpalata Tripathi • \\ Lity Mohanty • Sujata Pujari
}

Received: 2 November 2009/Accepted: 14 September 2010/Published online: 2 October 2010

(C) Indian Society of Haematology \& Transfusion Medicine 2010

\begin{abstract}
Philadelphia chromosome $\left(\mathrm{Ph}^{1}\right)$-positive Chronic Myelogenous Leukemia (CML) in a child below the age of 3 years is extremely rare. We have reported such a case in a 3 year old male child. Peripheral blood smear revealed features of CML and karyotypic study showed $\left(\mathrm{Ph}^{1}\right)$ positivity. Biologic behaviour and prognosis are similar to that of adult-type of CML.
\end{abstract}

Keywords Adult-type $\cdot \mathrm{CML} \cdot$ Karyotype $\cdot \mathrm{Ph}^{1}$-positive

\section{Introduction}

Philadelphia chromosome $\left(\mathrm{Ph}^{1}\right)$-positive Chronic Myelogenous Leukemia (CML) in childhood is rare, constituting about $3 \%$ of childhood leukemias [1]. In children below 5 years, it is even rarer. Only modem of information is available in the form of case reports [2, 3]. Diagnosis of such cases can be made from peripheral blood smear examination, supported by karyotypic study. Though biologic behaviour and prognosis are identical to that of adult type, we are reporting this case because of its extremely uncommon incidence $[1,2]$.

\section{Case Report}

A 3 year old male child presented with fever, hepatosplenomegaly of 3 months duration. Hematological investigations revealed: hemoglobin-6.9 gm/dl, total leukocyte count (TLC) $-110 \times 10^{9} / 1$, total platelet count (TPC)-

A. Mishra $(\bowtie) \cdot$ K. Tripathi $\cdot$ L. Mohanty $\cdot$ S. Pujari

Department of Pathology, S.C.B. Medical College,

Cuttack 753007, Orissa, India

e-mail: aparajita74@yahoo.co.in
$620 \times 10^{9} / 1$, differential count (DC)-neutrophil-29\%, eosinophil-05\%, monocyte-06\%, lymphocyte-11\%, myelocyte-14\%, metamyelocyte-15\%, blast-05\% (Fig. 1). Fetal hemoglobin level was normal. Karyotypic study revealed Philadelphia Chromosome positivity (Fig. 2). A diagnosis of $\mathrm{Ph}^{1}$-positive type of $\mathrm{CML}$ was made and patient was sent to the oncologist where he was advised chemotheraphy with imatinib. He is under follow-up since the last 2 years, and is responding well to treatment.

\section{Discussion}

CML in childhood presents as one of the two clinically distinct syndromes, i.e., adult-type CML (ATCML), which is $\mathrm{Ph}^{1}$-positive, and juvenile CML, also known as Juvenile Myelomonocytic Leukemia (JMML), which is $\mathrm{Ph}^{1}$-negative [4]. Though ATCML or $\mathrm{Ph}^{1}$-positive CML is more common in children, it is very rarely encountered below the age of 5 years, whereas JMML is more common [1]. In children, this disorder predominates in females, whereas in adults it is more frequent in males [2].

Diagnosis of such cases in chronic phase can be made by hematological investigations [5]. However, in children below 5 years, the possibility of JMML should be ruled out, for which a fetal hemoglobin estimation and karyotypic analysis are essential.

Clinical presentation, diagnostic criteria, biologic behaviour and prognosis are same as conventional ATCML with a few exceptions [1, 2]. Splenomegaly, hepatomegaly, hyperleukocytosis, anemia and leukostatic signs and symptoms are more frequently encountered in children [2]. According to a study by Sokal et al., percentage of circulating blasts and spleen size are the most significant predictors of long term survival [5, 6]. 


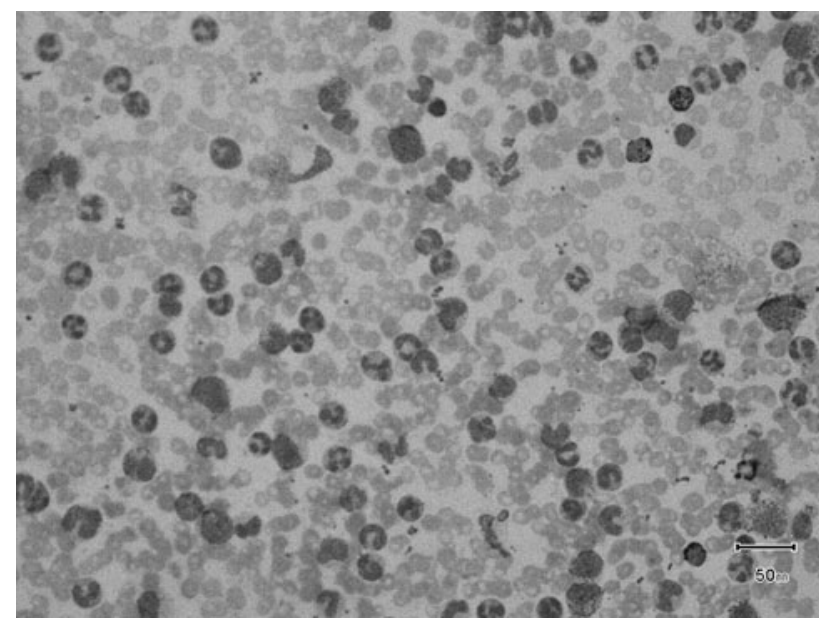

Fig. 1 Microphotograph showing peripheral blood picture of CML

\section{Conclusion}

$\mathrm{Ph}^{1}$-positive CML in a child below 5 years of age though extremely rare is possible.

\section{References}

1. Lichtman MA, Liesveld JL (2006) Chronic myelogenous leukemia and related disorders. In: Lichtman MA, Beutler E, Kipps TJ, Seligsohn U, Kaushansky K, Prchal JT (eds) Williams hematology, 7th edn. McGraw-Hill Companies Inc, USA, pp 1237-1294

2. Castro-malaspina H, Schaison G, Breire J, Passe S, Briere J, Pasquer A, Tanzer J, Jacquillat C, Bernard J (1983) Philadelphia chromosome-positive chronic myelocytic leukemia in childrensurvival and prognostic factors. Cancer 52:721-727

3. Rowe JM, Lichtman MP (1984) Hyperleukocytosis and leukostasis: common features of childhood chronic myeloid leukemia. Blood 63:1230

4. Roberts IAG, Dokal IS (2001) Adult-type chronic myeloid leukemia. In: Lilleyman J, Hann I, Blanchette V (eds) Pediatric hematology, 2nd edn. Churchill Livingstone, London, pp 419-436

5. Reichard KK, Larson RS, Rabinowitz I (2009) Chronic myelogenous leukemia. In: Green JP, Foerster J, Rodgers GM, Paraskevas F, Glader B, Arber DA, Means RT Jr (eds) Wintrobe's clinical hematology, vol 2, 12th edn. Lippincott Williams and Wilkins, USA, pp 2006-2030

6. Goldmann JM, Mughal TI (2005) Chronic myeloid leukemia. In: Hoffbrand AV, Catovsky D, Tuddenham EGD (eds) Postgraduate hematology, 5th edn. Blackwell Publishing, Wiley India Pvt Ltd, New Delhi, pp 603-618
Fig. 2 Photograph of karyotypic study showing Philadelphia-chromosome positivity

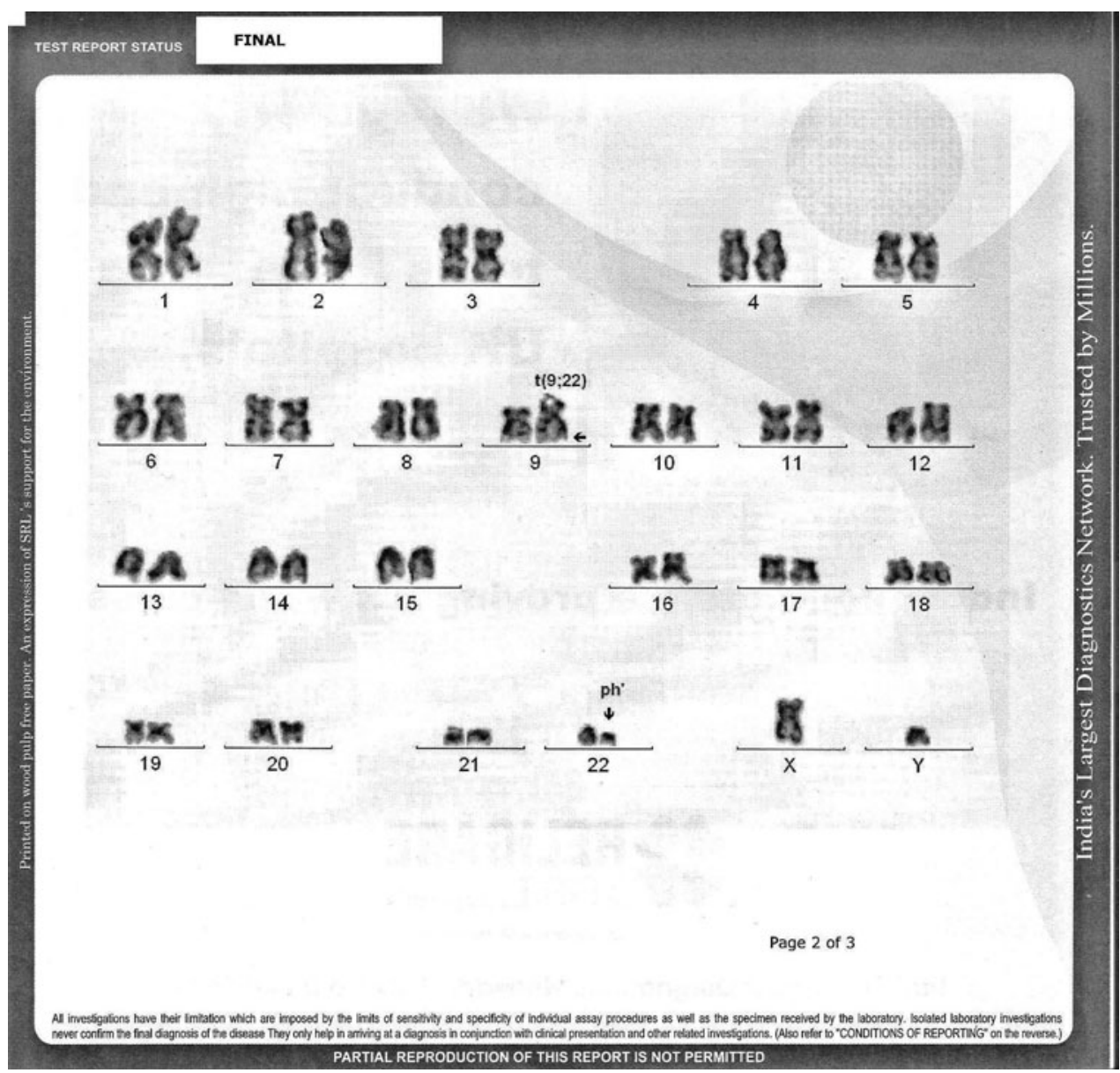

